\title{
Promoting high school students' physics identity through explicit and implicit recognition
}

\author{
Jianlan Wang ${ }^{1, *}$ and Zahra Hazari ${ }^{2}$ \\ ${ }^{1}$ College of Education, Texas Tech University, Lubbock, Texas 79409, USA \\ ${ }^{2}$ STEM Transformation Institute, Florida International University, Miami, Florida 33199, USA
}

(Received 14 April 2018; published 21 September 2018)

\begin{abstract}
This study is focused on student recognition beliefs as related to a role identity development. More specifically, using the theoretical framework of physics identity and emotional scaffolding, we investigate the impact of two types of recognizing strategies, i.e., explicit (ER) and implicit recognizing (IR), on high school students' sense of recognition and physics identity. ER is teachers directly conveying their acknowledgment of students' qualities or abilities, such as acknowledging good work and expressing faith in student ability, and IR is teachers indirectly acknowledging students' qualities or abilities via assigning them a position or a task that demands those qualities or abilities, such as valuing student opinions and assigning a challenging task. Through six longitudinal surveys for one year, we trace the physics identity development of 134 students from three high school physics classes as well as aspects related to physics identity construction including interest, competence beliefs, and sense of recognition. The patterns suggest that the recognizing strategies used by the teachers relate to a positive shift in students' sense of recognition, which in turn facilitates the development of a physics identity. The postinterviews with six students from the three classes reveal possible mechanisms by which ER and IR strategies are internalized by students. Our findings indicate that the synergy with ER and IR strategies used as well as the nature of the activities (i.e., attainable success) are critical features of effective teacher recognition that can be internalized by the student.
\end{abstract}

DOI: 10.1103/PhysRevPhysEducRes.14.020111

\section{INTRODUCTION}

One critical objective of science, technology, engineering, and math (STEM) education is to enhance students' enrollment and persistence in STEM careers as an answer to the increasing demand for STEM majors [1]. A salient problem with respect to accomplishing this objective is the low retention rate in college STEM fields, especially the physical sciences. According to the National Science Board [2], one-third of the postsecondary students who enrolled in 4-year institutions in the academic year 20032004 left STEM fields. The area of physical sciences has the lowest retention rate. Only $43 \%$ of freshmen in the academic year 2003-2004 who had plans to major in this area persisted. Much research has been conducted to promote students' performance and success in science, but primarily from the cognitive perspective, such as conceptual understanding $[3,4]$, reasoning $[5,6]$, critical thinking [7,8], and argumentation [9,10]. Students' emotional state, as another outcome, has been found critical

*jianlan.wang@ttu.edu

Published by the American Physical Society under the terms of the Creative Commons Attribution 4.0 International license. Further distribution of this work must maintain attribution to the author(s) and the published article's title, journal citation, and DOI. for engagement and perseverance in science [11-13]. In this study, we investigate high school students' emotional reactions to physics via the lens of physics identity, specifically the component of recognition.

Disciplinary role identity refers to how a student sees themselves with respect to a specific field in a specific context [14]. Studying how positive relationships are formed between students and subject matter is important because such relationships can facilitate not only persistence but also academic performance [15]. Without such positive relationships, an innovative reform may not have the intended effect. As Rosiek [16] points out that without a positive attitude towards inquiry, students might perceive uncertainty in inquiry as their lack of ability or knowledge rather than a necessary step in their investigation. Teachers' recognition of students' competence or potential is an effective strategy in fostering their disciplinary identity [17] within specific contexts [13]. However, little research has explicitly investigated the impact of teachers' recognition strategies on students' identity development. We explore this issue in the context of high school physics classes. Through longitudinal surveys and interviews from three high school physics classes, we examine the impact of two categories of recognition strategies, i.e., explicit and implicit recognition, on high school students' physics identity. 


\section{THEORETICAL FRAMEWORK}

\section{A. Physics identity}

Identity is a perceptual affective construct with which people classify themselves into various categories [18]. It involves internal conceptualization in terms of labeling "self" with pre-established social constructs, such as gender, career, and personality, and external manifestations in terms of taking actions that align with the labels of self. The self, namely, narrative self [19], is a result of accumulating and internalizing immediate and prior experiences (minimal self) that aligns with long-term goals (working self) [20]. Thus, identity can be applied to understand intentions of actions and predict future actions. The internal and external modalities of identity determine that it can be gauged through narration (narrated identity) or performance (performed identity) [14]. In this study, we focus on narrated identity because of our interest in understanding students' internal conceptualization of identity in response to their accumulated experiences in their physics class (Fig. 1).

There are different types of identities including personal, social, and role identities [17]. Personal and social identity, as labels of personal characteristics and social groups, are more insusceptible to specific moments, events, or emotional states than role identity, which is the perception of self in a specific context [21]. In our case, physics identity is a role identity, which is whether people see themselves as a "physics person" because of their experiences while playing the role of a physics student [13]. Developing a disciplinary role identity can bolster sense of belonging to as well as persistence in a field [22]. It is shaped by personal identity (e.g., I am outgoing) and social identity (e.g., I am a woman), particularly when these other identities are mismatched with a physics role identity (i.e., what it means to see oneself as a good physics student). Physics identity is also shaped by experiences with physics (e.g., my first physics lab report was praised by my teacher).

In this paper, we adopt the lens of physics identity to examine the impact of high school students' experiences with physics learning, particularly recognition experiences, on their physics identity. According to this theory, the

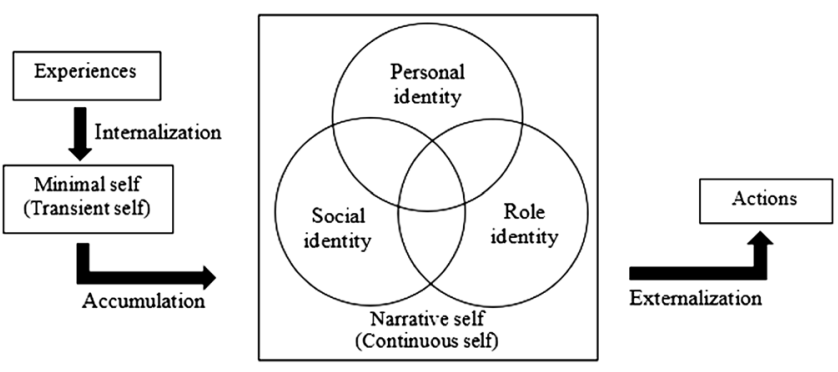

FIG. 1. Internal and external modalities of identity. construction of physics identity is supported by three components: interest (desire to learn physics), competence, or performance (self-perceived capabilities of successfully performing activities and understanding physics), and recognition (belief of being recognized by others as a physics person). Recognition is one promising lens to understand the relationship between teachers' emotional scaffolding and students' emotion in physics. To separate the two concepts, we use "recognition" to refer to internal recognition conceptualization (i.e., students' feeling of being recognized as a physics person), and recognizing strategy for external recognition manifestations (i.e., strategies of high school physics teachers in recognizing students as a physics person) throughout this paper. In the next section, we will illustrate recognizing as a strategy of emotional scaffolding that can potentially leverage students' sense of recognition and their role identity.

\section{B. Emotional scaffolding}

Wood, Brunner, and Ross [23] develop the theory of scaffolding that specifies how a teacher should facilitate student learning. In the situation of students performing a task beyond their unassisted efforts, a teacher needs to scaffold by "controlling those elements of the task that are initially beyond the learner's capacity, thus permitting [the learners] to concentrate upon and complete only those elements that are within [the learners'] range of competence" (p. 90). The teacher needs to continuously probe students' progress and adjust supports as learners' cognition develops. Puntambekar and Hübscher [24] identify four key features of scaffolding: intersubjective (teachers and students share the same goal and ownership of a task), ongoing diagnosis (teachers gauge students' progress in a task), calibrated support (teachers adjust their control of the elements in a task), and fading (teachers remove scaffolding and hold learners accountable for a task). The theory of scaffolding has been mainly applied to cognitive learning. Students' emotional learning is another important indicator of their well being and success in school $[16,25,26]$.

Emotional learning is defined as the process of students understanding and managing emotions, setting and achieving positive goals, establishing positive relationships with others, and making responsible decisions [27,28]. In this study, we adopt the aspect of emotion awareness and management [27], i.e., students' self-awareness of physics identity and emotional states such as volition, perseverance, and frustration. As neophytes in a domain, students are developing their sense of belonging and emotional affiliation. Teachers need to scaffold student emotional learning by controlling the elements beyond their emotional capacity, such as their attitude towards critics and their ability to handle drawbacks and even failures. Rosiek [16] introduces two types of emotional scaffolding: scaffolding with implicit versus explicit efforts. The former is to enact scaffolding without the instruction of the objective or 
TABLE I. Codes for recognizing strategies.

\begin{tabular}{|c|c|c|c|}
\hline \multirow[t]{4}{*}{ Teacher recognizing (T-R) } & Explicit recognizing (ER) & Address success (ER-1) & $\begin{array}{l}\text { e.g., Acknowledge good work, Reference } \\
\text { student ideas }\end{array}$ \\
\hline & & Address potential (ER-2) & $\begin{array}{l}\text { e.g., Express faith in ability, Encourage } \\
\text { science classes or activities }\end{array}$ \\
\hline & Implicit recognizing (IR) & Address responsibility (IR-1) & $\begin{array}{l}\text { e.g., Assign a challenging task, Express } \\
\text { expectation on result }\end{array}$ \\
\hline & & Address position (IR-2) & $\begin{array}{l}\text { e.g., Designate to authority or expert } \\
\text { position, Value student opinions }\end{array}$ \\
\hline
\end{tabular}

strategy of scaffolding, and the latter is to bring the practice of scaffolding to the foreground so that students are aware of why, how, and to what direction they are scaffolded. Drawing on the distinction between explicit and implicit scaffolding, we define the explicit recognizing (ER) strategy as teachers directly conveying their acknowledgment of students' qualities or abilities in physics, and the implicit recognizing (IR) strategy as teachers indirectly acknowledging students' qualities or abilities via assigning them a position or a task that demands those qualities or abilities.

As shown in Table I, we identify two types of ER: (i) addressing students' success. Examples would be expressions like "good job," "that's a brilliant idea," and "you have made a great contribution;" (ii) addressing students' potential of success, such as "you should major in physics in college," "I see your potential to be a physicist," and "I will write the recommendation letter for you." Similarly, we identified two types of IR: (i) addressing students' responsibilities by assigning a challenging task or setting up high expectations. Examples include teachers encouraging students to answer a hard question, or teachers expecting students to explore alternative solutions in a lab; (ii) addressing students' position as experts rather than novice learners. Examples would be teachers directing students to their peer for the answer to their question and teachers working with students side by side to accomplish a difficult task.

\section{EMPIRICAL STUDIES}

There is tendency of negative shifts in student attitudes towards physics at the college level [29-31]. This phenomenon is not limited to college since emotional reactions to physics also deteriorate in high school [13] as well as towards science in general at the secondary level [32-34]. Speering and Rennie [32] in a longitudinal study found that the participating students were less enthusiastic about science as they transited from elementary to secondary school. Vedder-Weiss and Fortus [33] reported declining student motivation towards science in traditional secondary schools. Thus, in order to foster student engagement and perseverance in college physics, actions (e.g., recognizing strategies) are needed in high school as well as at earlier time points.

There is little empirical research examining teachers' recognizing strategies as an approach to scaffolding students' disciplinary role identity or other emotional learning outcomes. However, there are studies indicating the potential of both ER and IR. Praise aligns with our definition of ER because it is a verbal reinforcement of desired behaviors, attitudes, attributes, or accomplishments from students to boost their self-esteem [35,36]. Praise is strongly perceived to be positive by students and impacts students' motivation by boosting self-efficacy [37], enhancing feelings of competence and autonomy [38], creating positive feelings [39], and helping regulate task engagement [40]. On the contrary, there are arguments that praise has detrimental functions by overemphasizing performance [41], inviting rejection of praise due to insincerity [42], leading to inferences of low ability when given for easy tasks [43]. Henderlong and Lepper [36] identify effective praise as being truthful and based on performance from controllable factors (e.g., effort) rather than uncontrollable ones (e.g., ability), leading to perceived autonomy of task engagement, and conveying evidence of self-competence as well as realistic and moderate standards for success. The aforementioned studies have supported the potential of ER in supporting role identity development. On the other hand, they also suggest the complexity of ER since its impact may be affected by other variables.

IR wise, learning environment has been found accountable for student emotional learning. Speering and Rennie [32] ascribe students' decreasing enthusiasm towards science from elementary to secondary school to the change in teacher-student relationship and the way of teaching. Specifically, it is a change from a pressure-free environment where elementary teachers and students have the flexibility and autonomy in inquiry learning to a highstakes-test oriented environment where secondary teachers prioritize covering contents required by standards normally through direct instruction. It is also a change from a more cooperative and caring culture to a more fragmented and competitive one. Vedder-Weiss and Fortus [33] observe that student motivation is more stable in secondary "democratic" schools characterized by four unique features: (i) students and staff share decision making; (ii) students have the freedom to allocate their time to the subjects they choose; (iii) there are no required classes; (iv) staff facilitate students' learning based on their interest and need. The democratic secondary schools share similarities with the 
elementary science experiences discussed above in that students have autonomy, at least partially, in their learning.

In the context of physics, Hazari et al. [13] identify four teachers' social cues that may have significant impact on the development of high school students' physics identity: (i) physical cues refer to teachers gaining proximity to students through classroom arrangement. Exemplary strategies include teachers moving around to different students and allowing greater freedom in the class space; (ii) structural cues are the dynamic nature of the classroom allowing for alternating roles. Examples include teachers using various pedagogies or structure on short timescales and assigning and enforcing alternate roles for students; (iii) contextual cues are teachers capitalizing on students' thoughts, ideas, and experiences. Examples include teachers applying discussions to which students could meaningfully contribute and relate, and hands-on activities to establish real-life contextual relevance; (iv) social cues refer to teachers obscuring boundaries between teacher and student, such as teachers explicitly indicating that "no one gets left behind" and showing fallibility. The four social cues aim at granting students autonomy in learning and the role of knowledge constructors, or in the authors' words, lessening the social distance between students, teachers, and physics content. Those studies indicate that implicitly recognizing students by granting them autonomy or placing them at the position of capable learners may support their emotional learning.

As illustrated above, the existing literature have indirectly justified the potential of ER and IR in supporting students' identity. However, empirical evidence is lacking about the relationship between ER or IR strategies and students' physics identity development. It is also unclear how students would internalize ER or IR into their sense of recognition, i.e., a teacher may recognize a student from an observer's standpoint, but the student may not feel recognized. Furthermore, previous efforts have focused on ER or IR alone. The key features of scaffolding, especially fading [24], suggests a potentially synergistic combination of ER and IR. In this study, we focus on the impact of physics teachers' various recognizing strategies on students' physics identity development. Our teacher participants attended a two-day workshop halfway through the school year that exposed them to the research on physics identity and the importance of recognition. The workshop also discussed recognizing strategies as described above. Our data present the physics identity of students in these teachers' classes at several time points during the year, both before and after the workshop. Our research questions are as follows:

(1) What were the patterns of the students' physics identity development, particularly after the workshop for the teachers regarding recognition?

(2) What were the recognizing strategies applied by the teachers and how did they translate with respect to the students' sense of recognition?
TABLE II. Gender and ethnicity distribution in the three physics classes.

\begin{tabular}{lcccccc}
\hline \hline & $n$ & Male & Female & Hispanic & White & Asian \\
\hline Mr. S & 69 & 32 & 32 & 58 & 2 & 4 \\
Mr. C & 30 & 15 & 12 & 25 & 1 & 0 \\
Mr. F & 35 & 24 & 8 & 23 & 3 & 5 \\
\hline \hline
\end{tabular}

\section{METHODS}

\section{A. Participants and research design}

Our primary research method is longitudinal case study [44]. The participants were three experienced physics teachers, Mr. S, Mr. C, and Mr. F, and their students were from three urban high schools. All three schools were in Hispanic communities. There were 134 high school physics students in total, including 69 students from Mr. S's Advanced Placement (AP) physics, 30 students from Mr. C's AP physics, and 35 students from Mr. F's physics honors. The demographic composition in the three classes is summarized in Table II.

This study took place in the academic year of 20142015. We did not enact any interventions in fall 2014 but collected data about the students' identity and recognition with a prevalidated identity survey. In December 2014, we held a two-day workshop with the three physics teachers in which we debriefed the teachers with regards to their students' physics identity development to that point, and introduced the significance of physics identity, its key components, and instructional strategies that can help maintain or enable physics identity development. We specifically recommended recognizing strategies that the teachers had not done in fall 2014, including acknowledgment of students' success and potential [37], student-led exploration and discussion [32], high expectations conveyed to students [13], and activities that may facilitate recognition, such as teaching a physics topic to their family member or creating a physics video to share with others [45]. After the workshop, the three teachers committed to implementing some of the recognizing strategies, and we continued tracking students' identity and recognition in spring 2015. Finally, we conducted semistructured interviews [44] with 6 students from the three classes to gauge the ER and/or IR strategies that their teacher actually used and the impact of the strategies on their recognition.

\section{B. Identity survey}

The identity survey contained three categories of questions tapping the three components of physics identity. The categories of interest, competence or performance, and recognition contained 6 items, 13 items, and 3 items respectively. Some exemplary items were "I am interested in solving physics problems" (Interest), "I am confident in learning physics topics in class" (competence or 
performance), and "my physics teacher sees me as a physics person"(recognition). Each item has a 6-level Likert scale from not at all (0) to very much (5). We conducted the identity survey six times throughout the project: Day 1 (Sept. 2014), Day 2 (Oct. 2014), Day 3 (Jan. 2015), Day 4 (Feb. 2015), Day 5 (Mar. 2015), and Day 6 (May 2015). We also collected the students' demographic information in the first survey. The survey items had been validated by previous empirical studies $[13,17]$. In addition, we ran both exploratory factor analysis (EFA) and confirmatory factor analysis (CFA) on all the 22 items each time after the survey was taken. It was found that the 22 items clustered well into the three components as expected at all the 6 time points.

For each survey, we first calculated an individual identity score by averaging the item points $(0-5 \mathrm{pts})$ pertaining to each category of identity and then averaging the three categories, i.e.,

$$
\begin{aligned}
\text { individual identity }= & \left(\frac{\sum \text { interest item points }}{6}\right. \\
& +\frac{\sum \text { competency item points }}{13} \\
& \left.+\frac{\sum \text { recognition item points }}{3}\right) / 3 .
\end{aligned}
$$

Subsequently, we averaged the identity scores of the students from one class as the class identity score for that survey, i.e.,

$$
\text { class identity }=\frac{\sum_{i=1}^{n} \text { individual identity }}{n} .
$$

We also calculated an average interest score,

$$
\frac{\sum_{i=1}^{n} \frac{\sum \text { interest item points }}{6}}{n},
$$

average competence score,

$$
\frac{\sum_{i=1}^{n} \frac{\sum \text { competencyitempoints }}{13}}{n}
$$

and average recognition score,

$$
\frac{\sum_{i=1}^{n} \frac{\sum \text { recognition item points }}{3}}{n}
$$

for each class. Repeating the process for all six surveys, we collected six class identity scores, six class interest scores, six competence scores, and six recognition scores in total for each class. We plotted the data in linear graphs to compare the development of student identity, interest, competence, and recognition between the three classes.

\section{Interviews}

The teachers' implementation of recognizing strategies had an impromptu nature that it was unpredictable when and how the teachers would use recognizing strategies. For example, neither the teachers nor we could foretell when a student would be praised. Thus, we gauged the teachers' practice of recognizing narrated by students in post interviews. Students' narratives represent their perceptions of the recognizing strategies, which helps explicate the strategies that students are more likely to internalize into a sense of recognition. Two students from each of the three teachers participated in the post semistructured interview. Convenient sampling was used that the six students were the volunteers from the three classes. We collected the six students' academic background information from the first survey, including their average grade in previous highschool science classes, average grade in previous highschool math classes, and career intention. The major themes in the interview protocol included students' perception of their physics identity, their sense of being recognized, and teacher recognizing strategies. For example, questions included "Do you consider yourself a physics person? Why?", "Anything special stand out regarding Mr. C/Mr. S/Mr. F's teaching? Why do you like it?", and "Do you feel like you were ever recognized by Mr. C, Mr. S, or Mr. F as a physics person? What did he do to make you feel that way?" We transcribed all the interviews and coded teacher recognizing strategies (Table I). Interrater agreement was achieved through discussion.

\section{FINDINGS}

In this section, we used the survey data to address the first research question and the interview data to answer the second question.

\section{A. Q1. What were the patterns of the students' physics identity development, particularly after the workshop for the teachers regarding recognition?}

We plotted in Fig. 2 the average scores (maximum 5 pts) of identity, interest, competence, and recognition from the three classes. Generally, Mr. S's students were higher than students of Mr. C and Mr. F in all regards. Mr. C's students were slightly higher than Mr. F's. Mr. S's students maintained their physics identity whereas Mr. C and Mr. F's students' physics identity declined (Fig. 2_a). Student interest towards physics started high (around 4.5 out of 5 ), and then went down in all three classes. The interest of Mr. S's students dropped less (Figs. 2_b). Student competence beliefs shared a pattern like that of identity (Fig. 2_c), which indicates that the students did not develop self-esteem about their competence in physics after learning more about physics. Although student recognition started low compared to other components, it shifted positively in Mr. S's and Mr. C's classes and stayed flat 


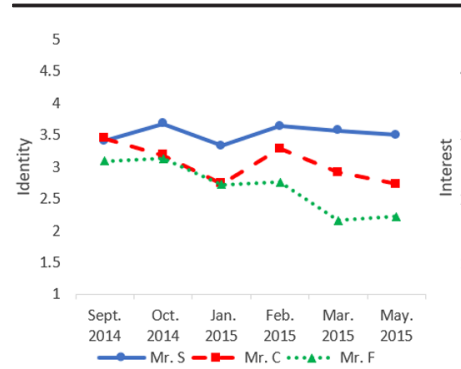

(a)

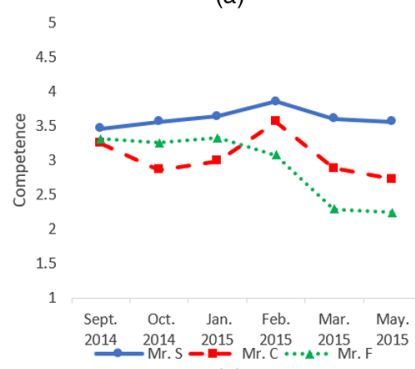

(c)

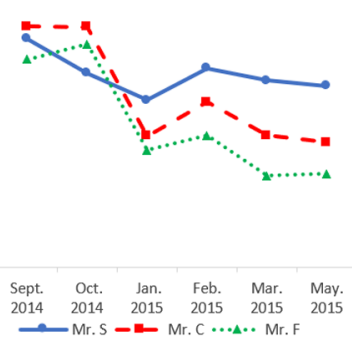

(b)

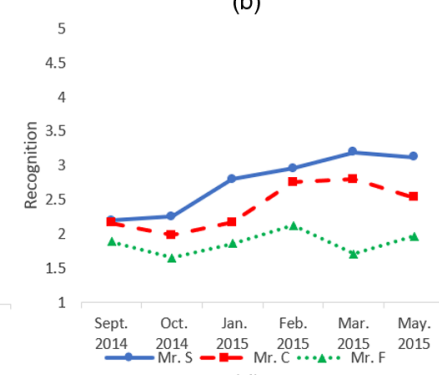

(d)

FIG. 2. Average score of class identity, interest, competence or performance, and recognition in the school year 2014-2015.

in Mr. F's class (Fig. 2_d). Overall, the physics instruction in the three classes had a nonpositive impact on the students' interest and competence beliefs, but a nonnegative impact on their sense of recognition.

Another salient pattern across the four diagrams is the spike that appeared at Day 4 (Feb. 2015). The spike suggests that the students' physics identity, interest, competence, and recognition ceased deteriorating and went back up, at least for a while. This fluctuation could result from measurement errors such as the absence of certain students while administering a survey. It also could be entailed by the recognizing strategies that the teachers had been implementing since the workshop. As stated earlier, the only research intervention we implemented was the workshop in December 2014, especially the recognizing strategies to which the teachers committed. Those strategies started in January and might take effect in February, which accounted for the fact that the spikes in Fig. 2 took place in February rather than January of 2015. In the next section, we capitalize on the interview data to gauge how the teachers were using recognizing strategies after

the workshop and how those strategies affected the students' sense of recognition and their physics identity.

\section{B. Q2. What were the recognizing strategies applied by the teachers and how did they translate with respect to the students' sense of recognition?}

\section{Interviewees}

The six interviewees were juniors at the time of the study. They are all Hispanic except for $\operatorname{Nate}(C)$ who identified himself as White. Table III is the summary of the six interviewees' background information. To remind the readers of the class each student was from, we used the notation of "student name (teacher code)" in this section. For example, Amanda(S) means that Amanda is from Mr. S's class. The six students varied in their achievement in previous high school science and math classes. Jessica (C) and Ashley(S) were 'A' students for both subjects while the others' grades were a little lower. As for the career intention (0 means not at all likely and 5 means very likely), Mike (F) and Nate(C) reported the highest interest towards physics careers. On the contrary, Ashley(S) expressed the least interest towards careers in physics or general science. Amanda(S), Jessica(C), and Mason(F) had no clear preference for their future career. Taken together, the students represent a range of different backgrounds, but may not be representative of all the students from the three classes. The small number of interviewees is one limitation of this study.

We plotted the six students' individual physics identity scores in Fig. 3. As indicated by the traces, Amanda(S), $\operatorname{Nate}(\mathrm{C})$, Jessica(C), and Mason(F) maintained their physics identity. Ashley(S)'s physics identity went up greatly, and Mike(F)'s dropped noticeably. Note that we were missing a few data points [e.g., Ashley(S), Day 3; Mason(F), Day 6]. To better understand changes in identity, we triangulated our understanding with the students' career intention from the first survey (Table III) and their narrated physics identity from the interviews. Amanda(S) had low intention towards a career in physics at the beginning of the project. She stated in the interview that she did not see herself as a physics person. Thus, Amanda(S) maintained a low physics identity although the identity trace revealed a small increase. Ashley(S) started with equally low intention

TABLE III. Interviewees' background information.

\begin{tabular}{|c|c|c|c|c|c|c|c|}
\hline & $\begin{array}{l}\text { Pseudo } \\
\text { name }\end{array}$ & Gender & $\begin{array}{l}\text { Average grade in } \\
\text { science classes }\end{array}$ & $\begin{array}{c}\text { Average grade in } \\
\text { math classes }\end{array}$ & $\begin{array}{l}\text { Likelihood of } \\
\text { physics career }\end{array}$ & $\begin{array}{l}\text { Likelihood of other } \\
\text { science career }\end{array}$ & $\begin{array}{c}\text { Likelihood of } \\
\text { nonscience career }\end{array}$ \\
\hline \multirow[t]{2}{*}{ Mr. S } & Amanda(S) & $\mathrm{F}$ & B & B & 0 & 1 & 2 \\
\hline & Ashley(S) & $\mathrm{F}$ & A & A & 0 & 0 & 5 \\
\hline \multirow[t]{2}{*}{ Mr. C } & Nate(C) & M & B & A & 5 & 3 & 1 \\
\hline & Jessica(C) & F & A & A & 1 & 1 & 0 \\
\hline \multirow[t]{2}{*}{ Mr. F } & Mike(F) & M & B & B & 5 & 1 & 2 \\
\hline & Mason(F) & M & B & B & 3 & 2 & 3 \\
\hline
\end{tabular}




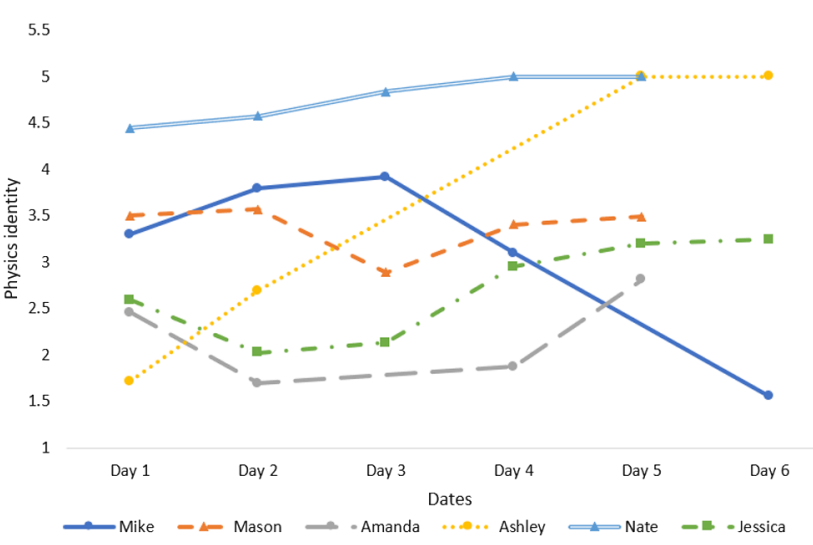

FIG. 3. Physics identity traces of the six interviewees.

towards a career in physics, but she clearly acknowledged her identity as a physics person in the interview. Thus, Ashely(S)'s physics identity likely ascended during the course of the school year. Nate $(C)$ started with a high career intention. In the interview, Nate(C) said that "I would call myself a physics person relative to my friends". Nate(C)'s language was more tentative about his physics identity compared to the other students. Nonetheless, Nate(C) appeared to maintain his physics identity. Although Jessica(C)'s career intention started low, she more readily accepted the possibility of having a physics identity. Jessica(C)'s physics identity increased. Mike(F)'s career intention started high, but he firmly rejected having a physics identity on the final survey and during the interview at the end of the year. Thus, Mike(F)'s physics identity deteriorated. Mason(F) stated in the interview: "did not consider myself a physics person but do enjoy learning about it." With his medium level of career intention at the beginning of the year, Mason(F) maintained his physics identity. Overall, the three sources of data (career intention question at the beginning of the year, longitudinal physics identity scale, and interviews at the end of the year) provide a better picture of these six students and how their physics identity changed over the course of the school year.

\section{Recognizing strategies}

All the six students except for Mike(F) stated in the interview that their teacher recognized them as a physics person. We drew on the interview data to identify ER or IR strategies the teachers used which may have translated into these feelings of recognition for students. Note that several of the ways in which students felt recognized were strategies discussed during the workshop.

$E R$.-Ashley(S) mentioned that $\mathrm{Mr}$. S recognized her as being talented and capable and recommended her for the second year of physics because "he saw the effort that I put in" (ER-1). When Ashley(S) told Mr. S that she wanted to go into engineering in the future, "he was like, okay, good, because I see you in that career" (ER-2). While talking about a presentation that $\mathrm{Amanda}(\mathrm{S})$ made in class, she stated that "I remember him (Mr. S) telling me like my explanation was good" (ER-1). She also mentioned that Mr. S encouraged her to join the science club where extracurricular science activities were provided (ER-2). Although Amanda(S) did not see herself as a physics person, she admitted that she joined the science club "mostly for him (Mr. S)" because Mr. S said that "you should join the science club."

Nate $(C)$ remembered that $\mathrm{Mr}$. C recognized his potential in physics by telling him that he was "ahead of what most people are in college" (ER-2), which made Nate(C) "really feel motivated to actually study further and see how far I can go." Nate $(\mathrm{C})$ also mentioned that he felt being recognized when he "scored the highest in one of the tests." He said that Mr. C did not share grades in class or praise him to his face, but he said he "knew that Mr. C was aware of my highest score" and "it was one example of when he recognized me." Jessica(C) mentioned that Mr. C "always acknowledged the work I did" (ER-1). She also mentioned that Mr. C "wanted me to take Physics 2" and he would "help me out because he feels like I can go somewhere with physics" (ER-2).

Mike(F) did not feel recognized by Mr. F. Mason(F) felt recognized but could not recall what exactly Mr. F said or did to make him feel that way. In his words, Mr. F "would see me as a physics person" because he assumed that Mr. F did "recognize me as someone that would enjoy the class and that would want to study this [physics]." We did not code this event as ER because there was no evidence of Mr. F applying any recognizing strategies. Mason(F) felt recognized probably because they thought that they have met the criteria perceived by their teacher with regards to being a physics person.

As illustrated above, Mr. S and Mr. C explicitly recognized students' success and potential, which was successfully conveyed to their students and positively impacted their students' sense of recognition. There was no direct evidence from the interview about Mr. F's ER strategies, but it does not mean that Mr. F did not explicitly recognize his students. It is likely that Mr. F applied ER strategies in a less translatable manner for the students we interviewed as compared to the students interviewed for Mr. S and Mr. C.

$I R$.-We identified two IR strategies implemented by all the three teachers: (i) scaffolding student autonomy in learning; (ii) students videotaping themselves teaching a physics concept to family members or demonstrating a physics concept.

Scaffolding autonomy in learning (IR-1).-All three teachers granted their students some autonomy in learning with challenging tasks, inquiry-oriented labs, raising openended questions, and/or student presentations. Through these approaches, the teachers recognized students as active and capable learners by addressing the students' responsibilities in learning. Most of the interviewees commented positively on this strategy. For instance, 
Amanda(S): "It [inquiry labs] helped me be more independent like with my work. I didn't have to depend on someone telling me all the steps that I have to do. I could just be more creative."

Jessica(C): "I like doing hands-on things. He never really told you what you were looking for until you actually got it yourself. So you got to do experiment, you got to realize something is connected. How you can use one thing you learn to affect the other, and you get whole different result... Yes, I thought it was nice. The whole point of that class was, we were very classmate oriented. We taught ourselves ... it was interesting."

Mason(F): "I think what he [Mr. F] really wanted us to do is actually think for ourselves ... when we would get the results it would be all, you know, because of us. It wouldn't be just because someone is telling us how to do it."

Amanda(S), Jessica(C), and Mason(F) felt accountable for their learning, which in turn strengthened their confidence in physics. However, not everyone liked the autonomy. Mike commented negatively on it.

Mike(F): "It was so vague sometimes that he [Mr. F] wouldn't even tell you how to do it. He's like just figure out yourself. So usually what happens is he always separated like two groups, the group that does it correct, the one that copies from instead of doing it by ourselves ... we would just spend time doing nothing and he would sometimes pass by and tell you to keep working but you know, then he will leave and you don't do anything anymore ... He didn't teach much."

Mike(F) interpreted the strategy of autonomy as Mr. F not doing his job. He perceived his struggling as him being incapable and ascribed it to the vague instruction from Mr. F. This strategy entailed Mike(F)'s negative emotions and undermined his physics identity. The reason might be that Mr. F assigned tasks that appeared to them to be beyond their range without further scaffolding and formative feedback. As Mike(F) described, Mr. F passed by and told students to keep working, but he did not check where the students were and whether they needed help. This is different from what Mr. S and Mr. C did.

Amanda(S): “... he (Mr. S) would give you hints to help you find your way through ..."

Ashley(S): “... he (Mr. S) gave us the opportunity but then if he saw that we were struggling he would go ahead and explain it right away ... At first just us and then after he will guide us. And then we will do it together.'

Jessica(C): "Mr. C would go around to check whether our work is right ... If not, when he finishes asking everybody, he would teach whatever he has to teach."

Clearly, Mr. S and Mr. C were enacting ongoing formative assessment during students' independent work and adjusting their support accordingly. To Mike(F), he did not feel supported as needed by Mr. F or his peers. In his words, the class was separated into one group that can finish a task and one group that cannot. Mike(F) labeled himself as "incapable" and quit trying. The capableincapable division in Mr. F's class was repeated by both students in the interview. Mike(F) and Mason(F) both mentioned that there were students presenting the solution to a problem or leading a discussion about a question in front of class. Mr. F placed the presenters at the position of authority who demonstrated their work and explained it to the class. Some students seemed to be the presenters more frequently than others, as $\operatorname{Mason}(\mathrm{F})$ and $\operatorname{Mike}(\mathrm{F})$ stated below.

Mason(F): "I think it might have been Anna, because she was one of the top students. Yeah, I think it might have been her that he [Mr. F] selected to lead the class."

Mike(F): "It [student presentation] was made in such an awkward manner where one kid knew it just did it and then the other kids are just standing there and the kid that knows it just explaining everything."

Considering the frequency of being selected as the presenter, it is reasonable to assume that the "top students," such as Anna, would feel recognized by Mr. F as a physics person. Mike(F) told us that he was selected once as the presenter. While sharing that experience, he said,

Mike(F): "It's [Mike(F)'s presentation] just hey, here's that. Look at it. I feel like most [students] didn't care, like if you're a student they feel that, they know that we're all going to do it so you know, why embarrass a kid, why laugh, this is doing it, the way that we really don't care much."

Mike(F) seemed to recall his presentation as an embarrassing experience. He perceived the presentation as an unpleasant assignment he had to do rather than something related to his learning as well as not being held to a high expectation by his peers. Thus, positive recognition in this case would be unlikely to occur. Thus, he did not feel recognized as a physics person by his peers or Mr. F. It is necessary to emphasize that Amanda(S) from Mr. S's class was a "B" student with much less interest but a much more positive recognition experience. Thus, the students' senses of recognition were related to their teacher's recognizing strategies. Mr. F's recognizing some students was accompanied with nonrecognition of others. That division may have deflated the collaborative learning environment in Mr. F's class and opportunities for IR. In contrast, Mr. C used white board presentations in his class. He required the students to present to him as a group on a white board about lab procedures or solutions to problems. That strategy fostered collaborative learning, as Jessica(C) commented below.

Jessica(C): "So he introduced a topic, we talked about it, together we came up with the variables, the procedure ... we divided in groups, so we moved and talked to each other, and then we got back together, he asked us, so what did you get?"

Jessica(C) used the words "we," "us," "together" multiple times, which suggests that she collaborated well with 
TABLE IV. The three teachers' different ways of implementing the strategy of videotaping.

\begin{tabular}{|c|c|c|c|}
\hline Teacher & Goal & Video sharing & Video length \\
\hline Mr. S & $\begin{array}{l}\text { Students taught family members } \\
\text { a physics concept }\end{array}$ & $\begin{array}{l}\text { Students played videos in class and } \\
\text { received feedback from peers }\end{array}$ & Long (5-8 min) \\
\hline Mr. C & $\begin{array}{l}\text { Students demonstrated their understanding of } \\
\text { a physics concept by applying it in real lives }\end{array}$ & $\begin{array}{l}\text { Mr. C played videos in class and commented } \\
\text { on the content of each video }\end{array}$ & Short $(5-10 \mathrm{sec})$ \\
\hline Mr. F & $\begin{array}{l}\text { Students demonstrated their understanding of } \\
\text { a physics concept by applying it in real lives }\end{array}$ & $\begin{array}{l}\text { Mr. F did not play the videos in class but } \\
\text { assign it for extra credits }\end{array}$ & Short $(10-15 \mathrm{sec})$ \\
\hline
\end{tabular}

her peers. With the strategy of scaffolded autonomy in learning, i.e., supported through some structure (e.g., group white board, specific goals) and formative feedback, the students of Mr. S and Mr. C developed a sense of connection to the content and the learning community. Such connection was lacking in Mr. F's class due to the capable and incapable division. Thus, we coded the autonomy in Mr. S and Mr. C's classes as "IR-1," but not that in Mr. F.

Videotaping (IR-2).--According to the interview, all the three teachers applied this strategy in spring 2015 but in different ways (Table IV). The students in Mr. S's class were videotaping themselves teaching the concept of diffraction after they had learned it to family members who did not know physics. Afterwards, the students shared their video in class one by one, during which they commented on each other's videos like real teachers did. As Ashley(S) and Amanda(S) commented below

Ashley(S): "It [the video] showed us how hard it is to be a teacher because once you know the concept and once you grasp it perfectly, okay, it makes sense in your head but when you try to put it into words to teach someone then nothing about that topic... Like it took me a long time. That's why it was hard but then at the end obviously like I didn't stop explaining until they [her parents] grasped the idea. And then they were like wow, that's cool like I never thought about it. And I was like yes, this is why science is awesome."

Amanda(S): "I always think like the highest level of knowledge is being able to teach someone else something and being able to help them understand. So I guess knowing that I was able to help other people understand the subject helped me know that I knew physics."

In taking up a position of expertise who knew the content with caring others, Ashley(S) and Amanda(S) gained a sense of recognition from their teaching experience and may have even enhanced their interest ("... this is why science is awesome") and sense of competence ("... helped me know that I knew physics"). In Mr. C's class, the students videotaped themselves demonstrating their understanding of a physics concept by applying it in real lives. Then Mr. C played each video to the class who already knew physics. and commented on the video and the physics concept involved. Mr. C took the position of authority. To students, they were not teaching but reporting to Mr. C their understanding of physics, as $\operatorname{Nate}(\mathrm{C})$ stated below
Nate(C): “Well, I mean, we didn't really go so deep into it because we already previously learned about it so it was just a quick refresher about that topic, because what he would do is he would first, when we would make our video, he would play it and then he would explain, he would ask us questions, oh, do you guys know why that happens? Do you remember this, this and that, and then he would then go deeper into the topic. But it was just a quick resemblance of that topic really. It wasn't meant to be something deep about it."

Mr. F deployed the videotaping activity as an assignment for extra credit. The students needed to record them swinging a bucket with water in it individually. Neither Mike(F) nor Mason(F) filmed the video. According to Mike(F), he noticed that his peer's video was $10-15$ sec long. Mr. F collected all the videos but did not play them in class. Thus, the video was probably not even a review of physics concepts to the students, but simply a task for credit.

Video length is another factor affecting the effectiveness of this assignment. The videos from Mr. S's students (5-8 $\mathrm{min}$ ) were much longer than that from the other two classes (less than $20 \mathrm{sec}$ ). A longer video allowed students to demonstrate more of their understanding and required more planning on the part of the student. Specifically, a video of 6-10 sec of a physics demonstration carried very limited information with regards to students' understanding, particularly since is required no narration. Nate(C) commented below while talking about the length of the video.

Nate(C): "I'm assuming the way he [Mr. C] thought was that if he would have given us a video and made us make a video up to like a minute he probably thought we would have made it complicated and it would have probably been too complicated or too time consuming. So he just wanted to make something quick and fun for us... they [peers] just thought it [videotaping] was funny and we had a fun time with it really. That's what it was mainly for, to have fun... It didn't really change it [physics identity] that much because it was just a seven second video, it's just a little project we did on the side."

Nate(C)'s interpretation seemed to be that Mr. C did not want to burden them by entrusting them with explaining the physics demonstration with a longer video project. Nate(C) assumed that Mr. C's intention behind the video was to "make something quick and fun". Correspondingly, he 
TABLE V. Recognizing strategies applied by the three teachers.

\begin{tabular}{lcccc}
\hline \hline $\begin{array}{l}\text { Recognizing } \\
\text { strategies }\end{array}$ & Description & Mr. S & Mr. C & Mr. F \\
\hline ER & $\begin{array}{c}\text { Address students' } \\
\text { success or potential }\end{array}$ & $\checkmark$ & $\checkmark$ & $x$ \\
IR-1 & $\begin{array}{l}\text { Autonomy in learning } \\
\text { IR-2 }\end{array}$ & $\checkmark$ & $\checkmark$ & $x$ \\
& $\begin{array}{l}\text { Recognition through } \\
\text { video project }\end{array}$ & $\checkmark$ & $x$ & $x$ \\
\hline \hline
\end{tabular}

perceived this activity as "a little project on the side" rather than something related to his learning. This activity had little impact on Nate(C)'s physics identity. Nate(C) did not feel recognized by $\mathrm{Mr}$. C, neither did Mason(F) nor Mike(F). Thus, we coded Mr. S's videotaping as IR-2 but not Mr. C and Mr. F's since their implementation did not convey IR strategy to students.

\section{Summary}

We summarized in Table $\mathrm{V}$ the recognizing strategies from the three teachers. The check mark " $\checkmark$ " means that a strategy was identified from the interview and it was effectively translated to students' sense of recognition. The cross mark " $X$ " means that a strategy was not identified from the interview or not effectively translated to students' sense of recognition. Apparently, Mr. S did best in recognizing students, followed by $\mathrm{Mr}$. $\mathrm{C}$, and then Mr. F. The pattern is aligned with that of recognition and physics identity shown in Fig. 2, which indicates that the recognizing strategies applied by the teachers may be a factor accounting for the differences in students' sense of recognition and eventually their physics identity.

\section{DISCUSSION}

In this study, we gauged students' emotional engagement with physics specifically examining their physics identity. Different from the negative trend identified by previous studies [29-31], we observed a maintaining trace of physics identity and increasing feelings of recognition in Mr. S's class. We attribute this, at least to some degree, to explicitly exposing Mr. $\mathrm{S}$ to the importance of recognition and his ability to implement recognizing strategies. As a first study, this paper reveals the ways in which teachers might effectively and ineffectively implement recognizing strategies after a workshop on the topic. The findings suggest specific ways of teachers recognizing students that may be effective and critical for regulation of students' physics identity. At a superficial glance, while the recognizing strategies used by the teachers may have appeared similar in format, they were substantively different because of the way they were framed in fostering student recognition. We identified two features that may influence the process of internalizing recognition for students: ER and IR synergy, and attainable success.

\section{A. ER and IR synergy}

Mr. F's students had the lowest average score on their physics identity and recognition (Fig. 2). Comparing his recognizing strategies with that of $\mathrm{Mr}$. S and Mr. F (Table IV), his implementation of recognition strategies, particularly with respect to more subtle forms of recognition such as IR, were likely not effective for many of his students. Mr. F did implement some IR strategies suggested by us, but $\operatorname{Mike}(\mathrm{F})$ perceived them as something unpleasant or embarrassing since they were not well scaffolded with a supportive classroom environment. In fact, $\operatorname{Mike}(\mathrm{F})$ could not recall Mr. F explicitly recognizing him. These findings echo claims made by studies regarding the importance of teacher acknowledgement that is direct and decisive [36]. ER alone may also be less effective since individuals often require multiple sources of recognition to see themselves more strongly as a certain type of person. Mr. C and Mr. S both implemented ER (Table IV), i.e., verbal acknowledgment, in a way that aligns with most of the criteria of effective praise [36]. For instance, they both successfully conveyed to their students their sincerity in ER, the evidence of student selfcompetence, and their appropriate expectations for the future. Nonetheless, Mr. C's students had a lower average score with respect to their physics identity and recognition than those of Mr. S. Different ways of implementing IR likely contribute to students' sense of recognition.

Using the videotaping activity as the tip of the iceberg, Mr. C did not truly place his students at the position of authority or as capable learners. Authentic IR should involve teachers facilitating students applying themselves in ways that enhance recognition by others. This may include strategies such as having students participating in authentic scientific inquiry like scientists, presenting their work to significant others, or decision making like important agents in a learning community $[32,33,46]$. For this to happen, it may be necessary to limit, if not remove, the hierarchy between teacher and students [13]. Blurring the boundary between teachers and students is not only a gesture but also an indication that teachers trust student agency and ability in learning. Considering the analogy of argumentation [9,47], if ER is the claim made by teacher about a student's capability, IR then serves as the evidence for that claim — an entrusting of responsibility to accomplish challenging tasks. An argument is strong when it has both elements. In this study, the progress made by Mr. S supports the importance of such a synergy between ER and IR.

\section{B. Attainable success}

In some cases, students demonstrated contrary responses to the same recognizing strategy, i.e., encouraging autonomy in learning. $\mathrm{Mike}(\mathrm{F})$ perceived the capable and incapable division in Mr. F's class and labeled himself as incapable. He was "forced" through independent work and student presentation without sufficient scaffolding to ensure he could accomplish challenges and be recognized. While struggles, 
mistakes, and failures are necessary and even expected in these types of activities, the lack of support and resources set up by Mr. F, maybe unintentionally, served to equate achievement with ability without leaving room for feelings of accomplishment based on growth or effort.

Mike(F) was an A or B student in science and math prior to this project as other interviewees (Table III). He even rated himself more highly in career interest towards physics than others, such as Amanda(S) and Ashley(S). There was no evidence that the students of Mr. S and Mr. C knew physics more or better than Mike(F) did. Actually, they also reported drawbacks during their autonomous learning. However, they perceived the drawbacks more positively because they had their peers or teacher available for support. The collaborative learning environment and the availability of teachers shielded the students from the emotions associated with failing. Similar to the counterpart in cognitive scaffolding, attainable success in the emotional dimension refers to scaffolding student emotional learning by initially controlling emotional loads within students' range of emotional competence, in this case, dealing with and overcoming failure [23].

\section{Conclusions}

The emotional dimension in physics learning is as important as the cognitive one because student affect, such as identity, drives their cognitive engagement and shapes their perceived relationship with the content and the learning community $[15,16]$. Becoming effective learners involves not only expanding the scope of knowledge and skills but also developing emotional competence necessary while facing challenges or barriers [28]. Similar to the idea that knowledge cannot be imparted to students [3,4], expected emotional states, such as engagement, grit, and perseverance, cannot be delivered but constructed by students with interpersonal and environment supports $[48,49]$. As found in this study, teacher recognizing is a promising approach to the support. Effective recognizing strategies are those internalized by students as a sense of recognition. The core of those strategies is reconciled words (ER) and deeds (IR) of teachers as a symbol of them truly trusting student capability, as well as the attainability of success that convinces students of their capability. Lastly, it is reaffirming that a teacher like Mr. S may have improved his practice through exposure to a very short workshop on recognizing strategies. While Mr. C and Mr. F's results were less exemplary, it is important to note that professional development can help teachers and that work to improve professional-development implementation is necessary to narrow the gap between research and practice.
[1] National Science Foundation, Preparing the Next Generation of STEM Innovators: Identifying and Developing our Nation's Human Capital (National Science Foundation, Washington, DC, 2010).

[2] National Science Board, What is the S\&E Retention Rate in U.S. 4-year Institutions? https://www.nsf.gov/nsb/sei/ edTool/data/college-10.html (2014).

[3] J. D. Gobert and J. J. Clement, Effects of student-generated diagrams versus student-generated summaries on conceptual understanding of causal and dynamic knowledge in plate tectonics, J. Res. Sci. Teach. 36, 39 (1999).

[4] C. Wieman and K. Perkins, Transforming physics education, Phys. Today 58, 36 (2005).

[5] D. Huffman, Effect of explicit problem solving instruction on high school students' problem-solving performance and conceptual understanding of physics, J. Res. Sci. Teach. 34, 551 (1997).

[6] G. J. Venville and V. M. Dawson, The impact of a classroom intervention on grade 10 students' argumentation skills, informal reasoning, and conceptual understanding of science, J. Res. Sci. Teach. 47, 952 (2010).

[7] T. v. Gelder, Teaching critical thinking: Some lessons from cognitive science, Coll. Teach. 53, 41 (2005).

[8] B. Miri, B.-C. David, and Z. Uri, Purposely teaching for the promotion of higher-order thinking skills: A case of critical thinking, Res. Sci. Educ. 37, 353 (2007).
[9] J. Wang and G. Buck, The relationship between Chinese students' subject matter knowledge and argumentation pedagogy, Int. J. Sci. Educ. 37, 340 (2015).

[10] J. Osborne, S. Erduran, and S. Simon, Enhancing the quality of argumentation in school science, J. Res. Sci. Teach. 41, 994 (2004).

[11] T. Andre, M. Whigham, A. Hendrickson, and S. Chambers, Competency beliefs, positive affect, and gender stereotypes of elementary students and their parents about science versus other school subjects, J. Res. Sci. Teach. 36, 719 (1999).

[12] H. B. Carlone, The cultural production of science in reform-based physics: Girls' access, participation, and resistance, J. Res. Sci. Teach. 41, 392 (2004).

[13] Z. Hazari, C. Cass, and C. Beattie, Obscuring power structures in the physics classroom: Linking teacher positioning, student engagement, and physics identity development, J. Res. Sci. Teach. 52, 735 (2015).

[14] J. M. Kane, Young African American children constructing academic and disciplinary identities in an urban science classroom, Sci. Educ. 96, 457 (2012).

[15] P. R. Aschbacher, E. Li, and E. J. Roth, Is science me? High school students' identities, participation and aspirations in science, engineering, and medicine, J. Res. Sci. Teach. 47, 564 (2010).

[16] J. Rosiek, Emotional scaffolding: An exploration of the teacher knowledge at the intersection of student 
emotion and the subject matter, J. Teach. Educ. 54, 399 (2003).

[17] Z. Hazari, G. Sonnert, P. M. Sadler, and M.-C. Shanahan, Connecting high school physics experiences, outcome expectations, physics identity, and physics career choice: A gender study, J. Res. Sci. Teach. 47, 978 (2010).

[18] J. P. Gee, Identity as an Analytic Lens for Research in Education, Rev. Res. Educ. 25, 99 (2000).

[19] S. Gallagher, Philosophical conceptions of the self: implications for cognitive science (2000).

[20] M. A. Conway and C. W. Pleydell-Pearce, The construction of autobiographical memories in the self memory system, Psychol. Rev. 107, 261 (2000).

[21] P. J. Burke, T. J. Owens, R. T. Serpe, and P. A. Thoits, Advances in Identity Theory and Research (Springer, New York, 2003).

[22] H. B. Carlone and A. Johnson, Understanding the science experiences of successful women of color: Science identity as an analytic lens, J. Res. Sci. Teach. 44, 1187 (2007).

[23] D. Wood, J. S. Bruner, and G. Ross, The role of tutoring in problem solving, J. Child Psychol. Psychiatry 17, 89 (1976).

[24] S. Puntambekar and R. Hubscher, Tools for scaffolding students in a complex learning environment: What have we gained and what have we missed?, Educ. Psychol. 40, 1 (2005).

[25] J. A. Durlak, R. P. Weissberg, A. B. Dymnicki, R. D. Taylor, and K. B. Schellinger, The impact of enhancing students' social and emotional learning: A meta-analysis of school-based universal interventions, Child Development 82, 405 (2011).

[26] J. E. Zins, M. R. Bloodworth, R. P. Weissberg, H. J. Walberg et al., The scientific base linking social and emotional learning to school success, J. Educ. Psychol. Consul. 17, 191 (2007).

[27] S. Collaborative for Academic and E. Learning, Safe and sound: An educational leader's guide to evidence-based social and emotional learning programs-illinois edition (Collaborative for Academic, Social and Emotional Learning, University of Illinois at Chicago, Chicago, IL, 2005).

[28] M. J. Elias, Promoting Social and Emotional Learning: Guidelines for Educators (Ascd, 1997).

[29] W. K. Adams, K. K. Perkins, N. S. Podolefsky, M. Dubson, N. D. Finkelstein, and C. E. Wieman, New instrument for measuring student beliefs about physics and learning physics: The Colorado learning attitudes about science survey, Phys. Rev. ST Phys. Educ. Res. 2, 010101 (2006).

[30] E. Brewe, L. Kramer, and G. O'Brien, Modeling instruction: Positive attitudinal shifts in introductory physics measured with CLASS, Phys. Rev. ST Phys. Educ. Res. 5, 013102 (2009).
[31] R. F. Moll and M. Milner-Bolotin, The effect of interactive lecture experiments on student academic achievement and attitudes towards physics, Can. J. Phys. 87, 917 (2009).

[32] W. Speering and L. Rennie, Students' perceptions about science: The impact of transition from primary to secondary school, Res. Sci. Educ. 26, 283 (1996).

[33] D. Vedder-Weiss and D. Fortus, Adolescents' declining motivation to learn science: Inevitable or not?, J. Res. Sci. Teach. 48, 199 (2011).

[34] R. E. Yager and J. E. Penick, Perceptions of four age groups toward science classes, teachers, and the value of science, Sci. Educ. 70, 355 (1986).

[35] G. S. Cannella, Praise and concrete rewards: Concerns for childhood education, Childhood Educ. 62, 297 (1986).

[36] J. Henderlong and M. R. Lepper, The effects of praise on children's intrinsic motivation: a review and synthesis, Psychol. Bull. 128, 774 (2002).

[37] A. Bandura, Self-Efficacy: The Exercise of Control (Macmillan, New York, 1997).

[38] E. L. Deci and R. M. Ryan, The general causality orientations scale: Self-determination in personality, J. Res. Pers. 19, 109 (1985).

[39] P. C. Blumenfeld, P. R. Pintrich, J. Meece, and K. Wessels, The formation and role of self perceptions of ability in elementary classrooms, Elem. School J. 82, 401 (1982).

[40] D. H. Schunk and B. J. Zimmerman, Social origins of selfregulatory competence, Educ. Psychol. 32, 195 (1997).

[41] A. Kohn, Why incentive plans cannot work (1993).

[42] D. E. Kanouse, P. Gumpert, and D. Canavan-Gumpert, The semantics of praise, New Dir. Attribution Res. 3, 97 (1981).

[43] W.-U. Meyer, Paradoxical effects of praise and criticism on perceived ability, European Rev. Soc. Psychol. 3, 259 (1992).

[44] D. Ary, L. Jacobs, and A. Razavieh, Introduction to Research in Education (Wadsworth Group, CA, 2002).

[45] R. Elmesky, "I am science and the world is mine": Embodied practices as resources for empowerment, School Sci. Math. 105, 335 (2005).

[46] J. Wang and G. A. Buck, Understanding a high school physics teacher's pedagogical content knowledge of argumentation, J. Sci. Teach. Educ. 27, 577 (2016).

[47] S. Toulmin, The Uses of Argument (Cambridge University Press, Cambridge, England, 1958).

[48] R. W. Blum, H. P. Libbey, J. H. Bishop, and M. Bishop, School connectedness-strengthening health and education outcomes for teenagers, J. School Health 74, 231 (2004).

[49] P. A. Jennings and M. T. Greenberg, The prosocial classroom: Teacher social and emotional competence in relation to student and classroom outcomes, Rev. Educ. Res. 79, 491 (2009). 